Arq. Bras. Med. Vet. Zootec., v.62, n.2, p.475-480, 2010

\title{
Testes físico-mecânicos e físico-químicos do couro da tilápia vermelha
}

\author{
[Physical-mechanical and physical-chemical tests of red tilapia leather] \\ L.C. Godoy ${ }^{1}$, E. Gasparino ${ }^{1 *}$, M.L.R.S. Franco ${ }^{1}$, N.P. Franco ${ }^{2}$, D.M. Dourado ${ }^{3}$ \\ ${ }^{1}$ Universidade Estadual de Maringá - UEM \\ Avenida Colombo, 5790 \\ 87020-900 - Maringá, PR \\ ${ }^{2}$ Centro de Aquicultura - UNESP - Jaboticabal, SP \\ ${ }^{3}$ Laboratório de Pesquisa em Biotecnologia e Ciências Ambientais - UNIDERP - Campo Grande, MS
}

\begin{abstract}
RESUMO
Realizaram-se testes físico-mecânicos e físico-químicos em couro de tilápia vermelha (Oreochromis spp.) a fim de testar a sua resistência. As amostras foram distribuídas em delineamento inteiramente ao acaso com dois tratamentos: no T1, procedeu-se à retirada do corpo-de-prova no sentido longitudinal e, no T2, à retirada do corpo-de-prova no sentido transversal. Para os testes de determinação da resistência à tração, alongamento e rasgamento progressivo, foi utilizado o dinamômetro EMIC, com velocidade de afastamento entre as cargas de $100 \pm 20 \mathrm{~mm} / \mathrm{min}$, em ambiente climatizado $\left( \pm 23^{\circ} \mathrm{C}\right.$ e UR do ar de $\left.50 \%\right)$, por 24 horas. A espessura do couro variou de 0,61 a $0,75 \mathrm{~mm}$, mas não houve diferença entre os sentidos analisados. O couro apresentou maior resistência à tração no sentido transversal, $25,89 \mathrm{~N} / \mathrm{mm}^{2},(\mathrm{P}<0,01)$, comparado ao sentido longitudinal, $14,20 \mathrm{~N} / \mathrm{mm}^{2}$. $\mathrm{O}$ alongamento foi significativamente $(\mathrm{P}<0,05)$ maior no sentido longitudinal, $80,8 \%$, em relação ao transversal, $62,6 \%$. Não houve diferença para o rasgamento progressivo entre os tratamentos. O couro apresentou teor de óxido de cromo de $3,8 \%$, graxa de $15,1 \%$ e pH e cifra diferencial de 3,5 e 0,5, respectivamente. Os valores nos testes de resistência e físico-químicos apresentados pelo couro indicam que ele pode ser utilizado para a confecção de vestuário e artefatos de couro em geral.
\end{abstract}

Palavras-chave: tilápia, couro, resistência, qualidade, fibras colágenas

\begin{abstract}
Physical-mechanical and physical-chemical tests were carried out on red tilapia leather. They were distributed in a completely randomized design with two treatments: $T 1=$ longitudinal body of proof; $T 2$ $=$ transversal body of proof. It was used the EMIC dynamometer for the tests of resistance to traction and elongation and the progressive tearing, with the speed of $100 \pm 20 \mathrm{~mm} / \mathrm{min}$ away between the charges, in an acclimatized room $\left( \pm 23^{\circ} \mathrm{C}\right.$ and relative humidity of 50\%) during 24 hours. The thickness of the analyzed leathers ranged from 0.61 to $0.75 \mathrm{~mm}$, without differing between the analyzed ways. The leather demonstrated a higher resistance to traction in the transversal direction $\left(25.89 \mathrm{~N} / \mathrm{mm}^{2}\right)(P<0.01)$, when compared to the longitudinal one $\left(14.20 \mathrm{~N} / \mathrm{mm}^{2}\right)$. However, the elongation was significantly higher $(P<0.05)$ in the longitudinal direction $(80.8 \%)$ when compared to the transversal $(62.6 \%)$. There was no significant difference for the progressive tearing between the treatments (longitudinal $=18.56 \mathrm{~N} / \mathrm{mm}$; transversal $=21.90 \mathrm{~N} / \mathrm{mm}$ ). The leather demonstrated a content of $3.8 \%$ of chromium oxide, $15.1 \%$ of grease, and $\mathrm{pH}$ and difference value of 3.5 and 0.5 , respectively. The values in the resistance and physical-chemical tests shown by the leather indicate that it may be used for clothing and leather artifacts in general.
\end{abstract}

Keywords: tilapia, leather, resistance, quality, collagen fibers

Recebido em 31 de agosto de 2009

Aceito em 31 de março de 2010

* Autor para correspondência (corresponding author)

E-mail: egasparino@uem.br 


\section{INTRODUÇÃO}

O avanço da tecnologia de produção, as exigências mercadológicas e o processo de hibridação ocorrido com a criação de algumas espécies de peixes foram os responsáveis pelo aparecimento de uma linhagem de tilápia, a tilápia vermelha (Oreochromis spp.) (Kubitza, 2000).

A tilápia vermelha apresenta coloração diferente da tilápia-do-nilo (Oreochromis niloticus), variando do rosa claro e do amarelo-alaranjado até o laranja-avermelhado. Essas variedades abriram espaço em mercados onde as tilápias de coloração original não são aceitas (Kubitza, 2000).

De acordo com Kubitza (2000), a tilápia vermelha é conhecida geneticamente, em todo o mundo, e pode haver até quatro espécies de tilápias na composição de alguns híbridos, baseando-se nos surgimentos dos mutantes vermelhos das espécies moçambique, que foram seletivamente hibridizadas com Oreochromis aureus, Oreochromis niloticus e Oreochromis urolepis hornorum. Esse autor relata que essas variedades são comercializadas em todo mundo como tilápia vermelha, porém podem apresentar características diferentes segundo a região onde foram estabelecidas. Além de a carne ser apreciada em todo o mundo por sua maciez, esta espécie destaca-se nas atividades de pesca esportiva e ornamental.

Segundo Larezzi (1988), a pele de peixe é um produto nobre e de alta qualidade, pois possui resistência peculiar. Contudo, a comercialização e a industrialização da pele de peixe enfrentam problemas de competitividade com outras peles exóticas existentes no mercado. Estes problemas ocorrem devido a dois fatores principais: o pequeno tamanho da pele e a sua fragilidade. Porém pela necessidade de se conhecer e comprovar a qualidade dessa matéria-prima, alguns trabalhos foram realizados com a finalidade de testar a resistência da pele de peixe (Souza, 2007).

De acordo com Souza (2004), vários são os fatores que influenciam na resistência do couro do peixe. Técnicas aplicadas no curtimento, no recurtimento e no engraxe, assim como, o acabamento, a estrutura histológica da pele e o sentido de retirada, foram avaliadas por vários autores (Machado et al., 2002; Souza, 2003; Souza et al., 2003; Kozuki et al., 2004).

O objetivo deste trabalho foi avaliar a resistência do couro de tilápia vermelha por meio de testes físico-mecânicos e físicos-químicos.

\section{MATERIAL E MÉTODOS}

O experimento foi realizado no laboratório de processamento de peles de peixes, da Universidade Estadual de Maringá. Foram utilizadas 500 peles de tilápia vermelha com média de peso de $800 \mathrm{~g}$, cada uma, provenientes de pisciculturas do Estado de São Paulo. As peles, retiradas dos filés com o auxílio de faca, foram congeladas até o momento do curtimento.

Para o processo de curtimento, as peles foram submetidas a várias etapas, de acordo com Hoinacki (1989) e Souza (2004): remolho, descarne, caleiro, desencalagem, purga, desengraxe, piquel, curtimento, neutralização, recurtimento, tingimento, engraxe, secagem e amaciamento. Após o curtimento, foram utilizados 20 couros para retirada do corpo-deprova, obtidos a partir da pele curtida. As amostras analisadas foram retiradas no sentido longitudinal e transversal ao comprimento do peixe, próximo à região dorsal (Fig. 1). Para os testes de resistência, foi utilizado o dinamômetro da marca EMIC, com velocidade de afastamento entre cargas de $100 \pm 20 \mathrm{~mm} / \mathrm{min}$, para análise de determinação da tração e alongamento (Associação Brasileira de Normas Técnicas (ABNT), 1997c) e análise da força de rasgamento progressivo (ABNT, 2005b).

Os corpos-de-prova foram retirados do couro (ABNT, 1990) com o auxílio de um balancim e, em seguida, levados para um ambiente climatizado, em torno de $23^{\circ} \mathrm{C}$ e umidade relativa do ar de 50\%, por 24 horas, conforme recomendação da ABNT (2006). Foram determinadas as medidas de espessura de cada amostra segundo a ABNT (2005a). 


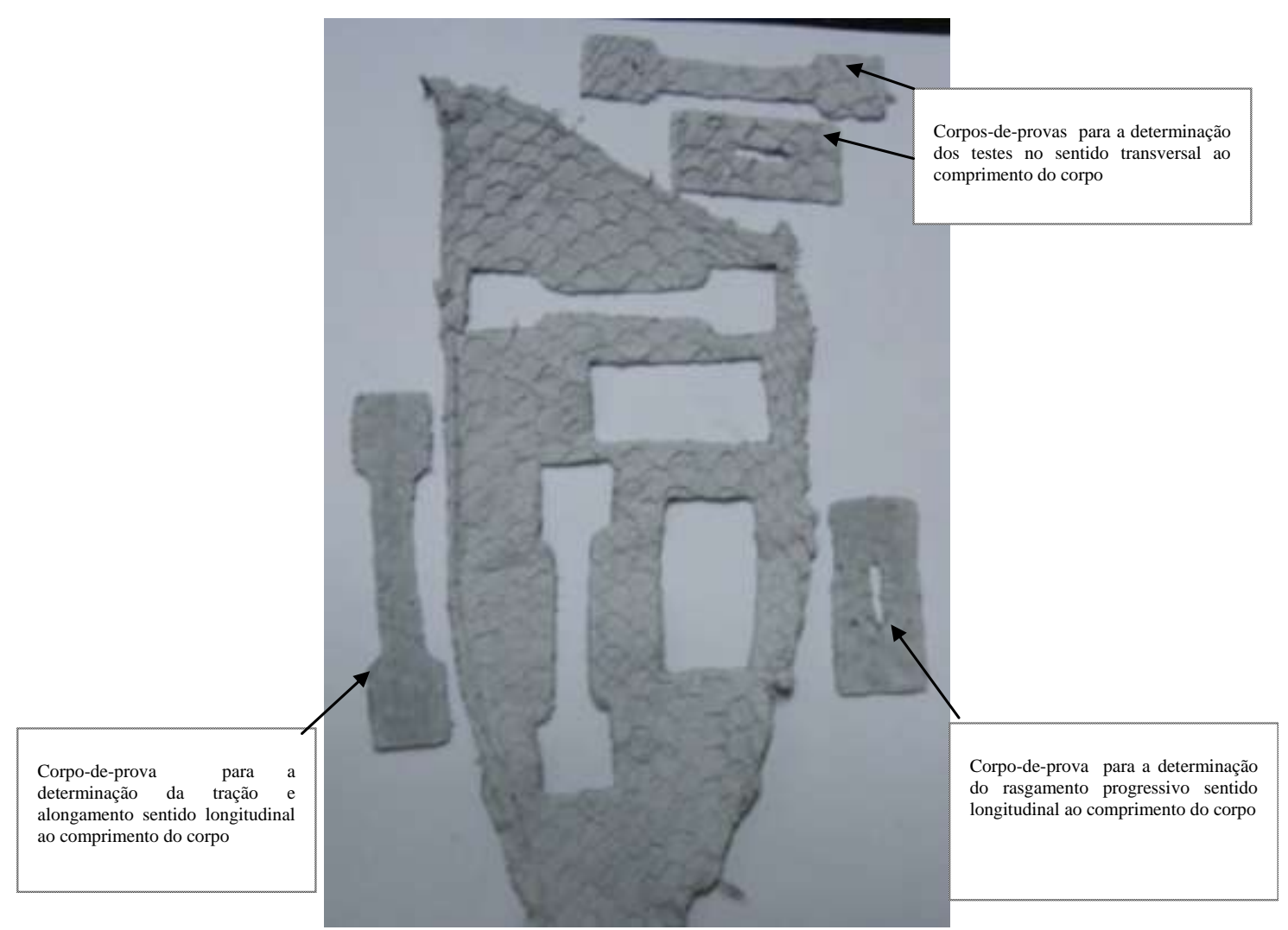

Figura 1. Retirada dos corpos-de-provas do couro de tilápia vermelha (Oreochromis spp.).

A análise fisico-química teve como objetivo indicar a quantidade de óxido de cromo que reage com o couro em conjunto com o $\mathrm{pH}$ e a cifra diferencial, e que determina a eficiência da curtição. A determinação do óxido de cromo no couro é dada pela oxidação da matéria orgânica por uma mistura de ácido sulfúrico, seguida de oxidação do cromo III a cromo VI, pela ação do ácido perclórico. O cromo VI é titulado com iodo.

A cifra diferencial é a diferença entre o $\mathrm{pH}$ do extrato aquoso diluído 10 vezes e o pH do extrato original. $\mathrm{O}$ pH e a cifra diferencial são indicativos da presença de ácidos fortes ou fracos livres no couro.

A determinação das substâncias extraíveis com diclorometano $\left(\mathrm{CH}_{2} \mathrm{Cl}_{2}\right)$, a do óxido de cromo $\left(\mathrm{Cr}_{2} \mathrm{O}_{3}\right)$, e a do $\mathrm{pH}$ e a da cifra diferencial do $\mathrm{pH}$ de um extrato aquoso foram realizadas segundo a ABNT (1997b; 1999ab).
Foi utilizado o delineamento inteiramente ao acaso, com dois tratamentos: $\mathrm{T} 1=$ com a retirada do corpo-de-prova longitudinal; $\mathrm{T} 2=\operatorname{com} \mathrm{a}$ retirada do corpo-de-prova transversal, com 10 repetições. A unidade experimental foi o couro.

Os resultados dos testes físico-mecânicos foram submetidos à análise de variância, com nível de 5\% de probabilidade (Banzatto e Kronka, 1995). Para os testes físico-químicos, as amostras foram compostas por seis unidades de couro, e procederam-se três análises para cada tipo de teste, sem se realizar análise estatística.

\section{RESULTADOS E DISCUSSÃO}

Os couros de tilápia apresentaram espessura média de 0,61 a 0,75mm nos corpos-de-prova obtidos no sentido longitudinal e transversal, respectivamente. Essa diferença não foi significativa. 
No sentido longitudinal ao comprimento do animal, a tração de ruptura foi de $14,20 \mathrm{~N} / \mathrm{mm}^{2}$ e a porcentagem de alongamento de $80,8 \%$, utilizando a força de $85,08 \mathrm{~N}$ para ocorrer a ruptura do corpo-de-prova. No sentido transversal ao comprimento do corpo, esses valores foram, respectivamente, $25,89 \mathrm{~N} / \mathrm{mm}^{2}$, $62,6 \%$ e $157,86 \mathrm{~N}$ (Fig. 2). Isto mostra que os couros analisados apresentam maior elasticidade (alongamento) no sentido longitudinal ao corpo do peixe, do que no sentido transversal (altura do peixe), foi necessária maior carga de força para ocorrer a ruptura no sentido transversal ou seja, houve maior resistência nos cortes de sentido transversal.

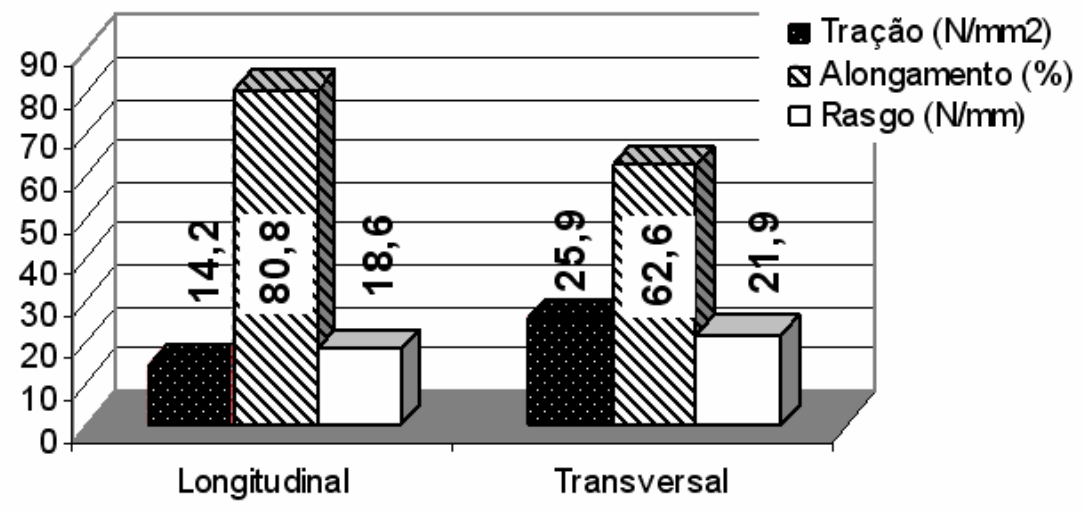

Figura 2. Valores médios dos testes de resistência do couro de tilápia vermelha analisado no sentido longitudinal e transversal do couro.

Quanto ao teste de rasgamento progressivo, não houve diferença significativa $(\mathrm{P}>0,05)$ quanto ao sentido do corte: $18,6 \mathrm{~N} / \mathrm{mm}$ E $21,9 \mathrm{~N} / \mathrm{mm}$ para os sentidos longitudinal e transversal, respectivamente.

De acordo com Souza (2003), o couro da tilápiado-nilo (peso corporal médio 500g) apresentou maior resistência à tração, $17,43 \mathrm{~N} / \mathrm{mm}^{2}$, e rasgamento progressivo, $17,86 \mathrm{~N} / \mathrm{mm}$, no sentido transversal ao comprimento do corpo do animal, enquanto o alongamento foi maior no sentido longitudinal, $77,2 \%$. Os resultados dos testes de resistência do couro de tilápia vermelha deste trabalho apresentaram as mesmas características de resistência para a tração e alongamento que o couro de tilápia-do-nilo observados pelo autor citado, ou seja, maior resistência à tração no sentido transversal e maior elongação ou elasticidade no sentido longitudinal. Todavia, os resultados de rasgamento progressivo diferiram entre os deste trabalho e os de Souza (2003), ou seja, ocorreu maior resistência do couro da tilápia-do-nilo no sentido transversal, enquanto no couro da tilápia vermelha não houve diferença entre os sentidos dos cortes.
Para comparar a qualidade de resistência do couro da tilápia vermelha e os demais couros de peixes, alguns fatores devem ser levados em consideração: o peso corporal das espécies analisadas, a técnica de curtimento aplicada no processamento das peles e a análise histológica das peles para verificar a arquitetura das fibras colágenas. Segundo Hoinacki (1989), essa arquitetura das fibras colágenas é muito importante para a resistência do couro. Greven et al. (1995) também afirmaram que a quantidade de espessas camadas de fibras colágenas tem efeito sobre as propriedades mecânicas da pele.

Segundo Vademécum... (2004), os valores de referência para couros curtidos ao cromo para vestuário, independentemente do tipo de recurtimento, deve ser de no máximo $60 \%$ para o alongamento na ruptura, no mínimo de $25 \mathrm{~N} / \mathrm{mm}^{2}$ de resistência à tração ou tensão e, no mínimo, $35 \mathrm{~N} / \mathrm{mm}$ para a resistência de rasgamento progressivo. Portanto, o couro da tilápia vermelha analisado não poderia ser utilizado para a indústria do vestuário, pois os valores obtidos foram menores que os recomendados pela literatura, quanto à tração e rasgamento 
progressivo, e apresentaram, também, elasticidade acima do exigido para a mesma finalidade.

O resultado obtido de óxido de cromo está relacionado com a proporção do curtente fixado às fibras colágenas. A quantidade de óxido de cromo presente nos couros analisados a partir das amostras está com valores dentro do indicado para um bom curtimento ao cromo e semiacabado, cujo valor deve ser de, no mínimo, $3,0 \%$, de acordo com Hoinacki (1989).
As substâncias solúveis em diclorometano são todas aquelas extraíveis da amostra pelo solvente. Essa análise indica o conteúdo de óleos e graxas no couro. O resultado observado na Tab. 1 é de $15,1 \%$, próximo ao recomendado pela Escola de Curtimento SENAI, que deve estar no máximo a $12 \%$ para o couro poder ser utilizado em vestuário (Hoinacki, 1989).

Tabela 1. Médias dos valores de determinação do óxido de cromo, teor de graxa, pH e cifra diferencial do couro da tilápia vermelha

\begin{tabular}{lccc}
\multicolumn{1}{c}{ Análise realizada } & \multicolumn{3}{c}{ Amostragem } \\
\cline { 2 - 4 } & \multicolumn{1}{c}{\begin{tabular}{c}
\multicolumn{1}{c}{ Determinação de óxido de cromo } \\
$\left(\mathrm{Cr}_{2} \mathrm{O}_{3}\right)^{1}-$ base seca $(\%)$
\end{tabular}} & 3,98 & 3,61 \\
\hline $\begin{array}{l}\text { Determinação de substâncias extraíveis em diclorometano } \\
\left(\mathrm{CH}_{2} \mathrm{Cl}_{2}\right)^{2}-\text { base seca (\%) }\end{array}$ & 15,53 & 15,17 & 14,70 \\
\hline Determinação do $\mathrm{pH}^{3}$ - base seca & 3,5 & 3,5 & 3,5 \\
\hline $\begin{array}{l}\text { Determinação da cifra diferencial em extrato aquoso } \\
\text { seca }\end{array}$ & 0,50 & 0,50 & 0,50 \\
\hline
\end{tabular}

${ }^{1}$ ABNT (1999a); ${ }^{2}$ ABNT (1997b); ${ }^{3}$ ABNT (1999b).

Os valores de $\mathrm{pH}$ estão dentro dos exigidos, tendo como valor mínimo 3,5 e cifra diferencial de, no máximo, 0,7, indicando que não há presença de ácido forte livre no couro, não prejudicando a sua resistência. As amostras estão dentro dos parâmetros recomendados pela ABNT, isto é, valor mínimo de $\mathrm{pH}$ igual a 3,5 e cifra diferencial máxima de 0,7 .

\section{CONCLUSÕES}

Os couros apresentaram maior elasticidade no sentido longitudinal e maior resistência no sentido transversal. $O$ sentido do couro não interferiu no teste de rasgamento progressivo. Quanto aos testes físico-químicos, os couros foram bem processados, mostraram estar dentro dos valores recomendados para a confecção de vestuário e podem ser utilizados para confecção de artefatos em geral, até mesmo vestuário fino, como é o indicado para os couros camurça.

\section{AGRADECIMENTOS}

Especial agradecimento à Secretaria Especial de Aquicultura e Pesca da Presidência da República pelo apoio na obtenção dos equipamentos do laboratório de curtimento, possibilitando a realização desse experimento.

\section{REFERÊNCIAS BIBLIOGRÁFICAS}

ASSOCIAÇÃO Brasileira de Normas Técnicas. NBR 10455: climatização de materiais usados na fabricação de calçados e correlatos. Rio de Janeiro, p.1-2.

ASSOCIAÇÃO Brasileira de Normas Técnicas. NBR 11035: corte de corpos-de-prova em couro. Rio de Janeiro, 1990. p.1.

ASSOCIAÇÃO Brasileira de Normas Técnicas. NBR 11062: couro - determinação da espessura. Rio de Janeiro, 2005. p.1.

ASSOCIAÇÃO Brasileira de Normas Técnicas. NBR 11055: couro - determinação da força de rasgamento progressivo. Rio de Janeiro, 1997a. p.1-4. 
ASSOCIAÇÃO Brasileira de Normas Técnicas. NBR 11041: couro - determinação da resistência à tração e alongamento. Rio de Janeiro, 1997b. p.1-5.

ASSOCIAÇÃO Brasileira de Normas Técnicas. NBR 11030: couro - determinação de substâncias extraíveis com diclorometano $\left(\mathrm{CH}_{2} \mathrm{Cl}_{2}\right)$. Rio de Janeiro, 1997b. p.1-3.

ASSOCIAÇÃO Brasileira de Normas Técnicas. NBR 11054: couros - determinação de óxido crômico $\left(\mathrm{Cr}_{2} \mathrm{O}_{3}\right)$. Rio de Janeiro, 1999a. p.1-5.

ASSOCIAÇÃO Brasileira de Normas Técnicas. NBR 11057: couro - determinação do $\mathrm{pH} \mathrm{e}$ da cifra diferencial. Rio de Janeiro, 1999b. p.1-3.

BANZATTO, D.A.; KRONKA, S.N. Experimentação agrícola. 3.ed. Jaboticabal: FUNEP, 1995. 247p.

GREVEN, H.; ZAMGER, K.; SCHWINGER, G. Mechanical proprieties of the Xenoplus laevis (Anura, Amphibia). J. Morphol., v.224, p.15-22, 1995.

HOINACKI, E. Peles e couros - origens, defeitos e industrialização. 2.ed. Porto Alegre: SENAI, 1989. 319p.

KOZUKI, H.T.; SOUZA, M.L.R.; GODOY, L.C. et al. Análise comparativa da resistência dos couros da carpa prateada: corpos-de-prova obtidos no sentido longitudinal e transversal ao comprimento do couro. In: AQUACIÊNCIA 2004, Vitória. Anais... Vitória: Aquabio, 2004. p.333.
KUBTIZA, F. Tilápia: tecnologia $e$ planejamento na produção comercial. Jundiaí: F. Kubitza, 2000. 285p.

LAREZZI, A.D. Peles de peixes: matéria-prima para confecções, calçados e acessórios de moda. Setor Couro, v.19, p.8-9, 1988.

MACHADO, S.D.; DOURADO, M.D.; SOUZA, M.L.R. et al. Testes de resistência físicomecânico do couro do piavuçu (Leporinus macrocephalus) e tilápia-do-nilo (Oreochromis niloticus). In: AQUICULTURA BRASIL 2002, Goiânia. Anais... Goiânia: Simbraq, 2002.

SOUZA, M.L.R. Processamento do filé e da pele da tilápia-do-nilo (Oreochromis niloticus): aspectos tecnológicos, composição centesimal, rendimento, vida útil do filé defumado e testes de resistência da pele curtida. 2003. 169f. Tese (Doutorado) - Centro de Aqüicultura, Universidade Estadual Paulista, Jaboticabal, SP.

SOUZA, M.L.R.; GANECO, L.N.; NAKAGHI, L.S.O. et al. Histologia da pele do pacu (Piaractus mesopotamicus) e testes de resistência do couro. Acta Scienc., v.25, p.37-44, 2003.

SOUZA, M.L.R. Tecnologia para processamento das peles de peixe. Maringá: Eduem, 2004. 59p.

SOUZA, M.L.R. Tecnología para procesamiento de pieles de pescados. Maringá: Eduem, 2007. $61 \mathrm{p}$.

VADEMÉCUM para el técnico em curtión. 3.ed. Ludwigshanfen: Basf, 2004. 